\title{
Corporate real estate strategy in the UK and Malaysia
}

\begin{abstract}
Purpose: The purpose of this paper is to compare corporate real estate (CRE) strategies of companies in a mature market, the UK, with companies in an emerging market, Malaysia, and examine whether CRE strategy impacts on financial performance.

Design/methodology/approach: The methodology involved the analysis of the reporting of CRE strategies in company reports for two time periods, 1998 and 2003. Multivariate models were used to test the relationship between CRE strategy and financial performance.

Findings: The results show that a high percentage of companies have CRE strategies that map to the Nourse and Roulac framework, though some companies had alternative or no CRE strategies. Variations are apparent between the UK and Malaysia and between the time periods with differences in the clarity of reporting. The contribution of CRE strategy to financial performance is more significant in 2003.

Research limitations/implications: The testing of relationships based on another framework, would allow comparisons to be made with the current study in determining the potential of CRE strategy.

Originality/value: This study has been the first attempt to identify relationships between CRE strategy and the financial performance of companies and in doing so has raised other potential questions for further research.
\end{abstract}

Keyword: Corporate strategy; Real estate; Financial performance; Malaysia; United Kingdom; Multivariate analysis 